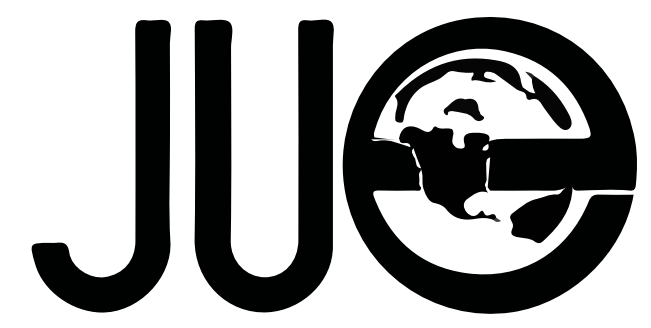

The Journal for Undergraduate Ethnography

Volume 5 | Issue 2

\title{
Rice, Risk and Ritual: What Agriculture and Religion Tell Us about State-Minority Relations among the Khmu of Northern Laos
}

\section{Anjana Ramkumar}

National University of Singapore, anjana.r@u.nus.edu

\section{ABSTRACT}

$\mathrm{n}$ examining state-minority relations in Southeast Asia, Scott (2009) argues that the attributes of 'hill tribes' are acts of political strategy designed to evade state capture. Cautioning against a binary between freedom and oppression, Jonsson (2012) calls for a historically and socially contextualized approach to state-minority relationships. This research contributes to this debate by focusing on religion and agriculture, which have been closely linked in highland societies. Swidden rice cultivation has traditionally been sacred, featuring religious rituals. However, state influences have driven a shift from swidden subsistence farming to sedentary commercial farming. This article investigates the effects of this transition on religion and agriculture amongst the Khmu in the Vieng Phouka district of Northern Laos. Ethnographic methods reveal significant secularisation in agriculture, with increasing economic rationalisation of decisions pertaining not only to agriculture but also to religious rituals. At the same time, selected state-introduced cash crops are being sacralised, particularly in scenarios with high risk. These observations indicate an amalgamation of religion and modern rationalisation. Such amalgamations can be understood as adaptations of the Khmu to maximise benefits, illustrating strategic agency suggested by Scott (2009). However, the agency is applied to engage with the state instead of resisting it, falling, as Jonsson (2012) suggests, outside the freedom-oppression dichotomy. 


\section{Introduction}

Religion and agriculture have been closely linked in highland societies of Southeast Asia, especially in contexts where economic, political, and religious domains are well integrated (Kirsch 1973). In such societies, sacred and secular acts are not differentiated, and agriculture, amongst other technical practices, has a religious significance and motivation (Kirsch 1973, 12). In particular, swidden rice cultivation has traditionally been considered sacred, with regular rituals performed during the agricultural process (Sprenger 2006). However, growing state influences on highlanders in the modern day have resulted in major agricultural change from swidden-based subsistence farming to sedentary commercial farming. This article investigates the effects of such state-driven agricultural transition on religious beliefs amongst the Khmu in the Vieng Phouka district of Northern Laos.

The Khmu are traditionally shifting agriculturalists who practice subsistence swidden farming, clearing forest lands in the hills by fire on a rotational basis to grow crops for consumption. However, the Lao state has been discouraging swidden farming for the past few decades as it considers the burning of forest land to be environmentally unfriendly. As such, development policies have been tailored to reduce swiddening in favour of lowland farming. With the formalisation of land tenure that took place after resettlement in the 1970s, villagers faced more restrictions on owning swidden plots as opposed to the informal system when they were in the hills. This reduction in access to swidden land means shorter fallow cycles, which then lowers fertility of the soil, making it less productive. Meanwhile, a growing regional market has made cash-crop farming more lucrative, and roads have improved the market access of the Khmu greatly, facilitating their move towards commercial farming (Thongmanivong and Fujita2006). Paddy-field farming of rice and cash crops is therefore becoming prevalent in Khmu villages. The restriction of shifting agriculture has also resulted in sedentary farming of mono-crops such as rubber and corn on hills previously used for swiddening (Thongmanivong and Fujita 2006). However, swiddening has not stopped completely and many Khmu continue to plant hill rice as a strategy for food security. Nonetheless, changes in agriculture are evident as the majority of Khmu households in the district now practice commercial agriculture (ibid).

While effects of these agricultural changes may be most evident in economic and political domains, their repercussions extend to $\mathrm{Khmu}$ religious beliefs as well. As Sprenger (2006) illustrates, the practice of swiddening amongst the Lameet (a highland minority ethnic group similar to the 
$\mathrm{Khmu}$ ) is not only one of physical survival but rather the centre of a system that holds together kinships and religious beliefs. Therefore, this article considers how the decline in swidden farming coupled with the advent of cash crop agriculture has impacted the connection between agriculture and religion among the Khmu in Laos. It also analyses the extent to which sacredness prevails as a macro-concept in the Khmu society and how it has evolved in relation to modernity.

\section{Background}

The relationship of highland minorities with the state is a complex one, with different schools of thought trying to decipher the dynamics of this relationship. On one hand, Scott (2009) argues that the characteristic attributes of south-east Asian 'hill tribes' such as the Khmu are actually adaptations designed to evade both state capture and formation - Acts of political strategy that runs counter to the conventional notions that they are 'primitive. The strategies he analyses include adaptations of agriculture, where he specifies shifting agriculture as a form of 'escape' agriculture, in that shifting agriculture has a high degree of mobility which helps the minorities evade the state (Scott 2009, 190-1). However, Scott's argument is based on a confrontational stance between the state and minorities that involves a high degree of generalisation by the author. Jonsson (2012) warns against the moral binary set up by Scott between freedom and oppression, and instead urges for an approach that contextualises the relationship historically and socially. In arguing for greater fluidity in charactering state-minority relations, Jonsson also opens up the possibility that the relationship may not be completely antagonistic.

In the past few decades, as Scott acknowledges, the development of state technologies with the advent of modernity (post World War II) has made it near impossible for highlanders to both evade and resist the state (Scott 2009, 11). Negotiations of minorities with the state in modern day revolve very much around security and development - two of the state's primary concerns (Phosena 2005, 91). One of the main ways in which the state 'develops' highland societies is via modernising agriculture. Given the two contrasting arguments between Scott and Jonsson, this paper focuses on agriculture among the Khmu society in an attempt to characterise state-minority relations. Although Scott disclaims the applicability of his argument to modern day (Scott $2009,11)$, residuals of past relations may well extend into the present, at least in the attitudes of highland minorities towards the state, making such a study relevant. Furthermore, pursuing this research allows us to identify where the current state-minority relations in Lao stand in the wide spectrum between the successfully evasive and strategic minorities whom Scott describes, and minorities who are subjected to the complete penetration of the state, as commonly perceived.

While Scott (2009) perceives agriculture to be a key adaptive strategy, agriculture is at present also one of the main modes of state intervention as mentioned earlier.Thongmanivong and Fujita (2006) analyse how developmental policies have led to rapid agro-ecological landscape changes in a study area comprising four villages in North Laos. The article shows that subsistence and swidden agriculture has decreased rapidly, with an increasing move towards a commercial and multifunctional use of the land, which includes planting cash crops such as rubber, sugarcane and non-timber forest products.

Such changes are quantified using data obtained on land usage, which indicate a decrease of $80 \%$ in upland (i.e. swidden) agricultural land from 1993 to 2000 (Thongmanivongand Fujita, 2006, 240). These changes are largely attributed to government policies on land and forest usage, which restrict traditional swiddening practices, a growing regional market for cash crops, which makes the agricultural transitions more lucrative and attractive, and development of roads, which greatly improve access to markets (Thongmanivong and Fujita 2006, 243). These are all 
evidence of how much more pervasive the state is at present, in line with Scott's argument that it is near impossible for minorities to avoid interacting with the state in the modern day.

While Thongmanivong and Fujita (2006) provide a geographical perspective to the landscape changes that are occurring, La-orngplew (2010) provides a more ethnographic understanding of a similar phenomenon, focusing on rubber planting in the highlands and analysing the roles of the various stakeholders in this phenomenon. Referring back to Scott's argument of hill tribes strategically adapting to negotiate their position vis-a-vis the state, she puts forth the argument that perhaps this ideology may still be applicable in the modern day by highlighting the active role that the villagers themselves play in adopting such commercial agriculture. In other words, she claims that commercial agriculture is not simply forced by the state on the highlanders in its pursuit of economic development, but rather is actively adopted by and adapted to by the agriculturalists (La-orngplew 2010). It should be noted that while most of Scott's work is embedded in the context of strategies to evade and resist the state, La-orngplew describes a case where minorities strategise to engage with the state. Thus, her argument also simultaneously supports Jonsson's claim that certain minority groups might possibly engage with the state under the appropriate conditions (Jonsson 2012). However, this concept of active engagement by minorities may need further investigation as to what their motivation is, for they may not necessarily have economic goals similar to the state's.

All the articles on agriculture mentioned above take a very functional approach focusing on the tangible, material and quantitative impacts of these changes. However, in order to fully characterize state-minority relations, it is helpful to focus on a less explored aspect of the $\mathrm{Khmu}$ society. As opposed to analysing structural changes at the societal scale, it is useful to investigate the intangible yet salient changes that take place at an individual scale due to interactions with the state. One of the few authors to have adopted this methodology is Evrard (2011), who analyses the contrasting resettlement experiences of Khmu groups who fought on opposing sides of the Indo-China war, by using the individual as his subject of study. Such an analysis then brings out intangible aspects of such state-minorities relationships, such as the emotions, beliefs and attitudes of the person who is experiencing resettlement, rather than focusing on a highland society that is resettled.

One way to apply such an approach to agriculture would be to focus on religious beliefs in highland society in relation to agriculture. To do this, it is necessary to get an understanding of how the system of agriculture works from the highlanders' perspectives, which requires an understanding of their worldview and religious beliefs.

In his classic work of anthropology, Kirsch $(1973,4)$ argues that the highland society functions as a single holistic unit, in which the divides between religious, political and economic dimensions are not well defined. He highlights the 'absence of radical distinction' between 'secular' acts and 'sacred' acts, where technical acts that are performed for survival have a religious aspect to them, which contributes to their validation (Kirsch 1973, 12). Thus, according to Kirsch (1973), there are no purely secular or purely sacred acts in highland societies. Kirsch argues that tribal religions fundamentally aim to maximise 'potency' and illustrates how ritual feasting and affinal relations (matrilineal cross cousin marriages in particular) are structured to reflect this end (Kirsch 1973, 18). In ritual feasting, the feast giver is elevated in social status and endowed with prestige as a 'reward', since the provision of feasts is evidence of innate 'potency' (ibid.). Similarly, greatest importance is placed on one's mother's brother amongst all relations gained through marriage since his enmity is believed to cause sterility - a grave threat to 'potency' (Kirsch 1973, 22). Thus, both feasting and managing affinal relations become religious acts in addition to being social ones (Kirsch 1973). 
Applying Kirsch's 'integrated' model to agriculture, it can be seen that the technical act of farming may contain a religious aspect to it as well, especially given that agriculture, being a primary mode of sustenance, is one the main source of 'potency' in a highland society. This religious dimension emerges clearly in Sprenger's study of swiddening practices amongst the Lameet, a Southeast Asian highland minority similar to the Khmu. Sprenger (2006) argues that the practice of swiddening by the Lameet is not only one of physical survival but rather the centre of a system that holds together kinship and religious beliefs. He illustrates this by taking the readers through the entire process of a swidden cycle, explaining how every stage is tied to affinal relationships with specific rituals performed for each of them (Sprenger 2006). Adopting both Kirsch's general lens and Sprenger's specific case study, it can be seen that agriculture, kinship and religion are tightly woven together, and to the Lameet themselves is a single act with three sets of meanings, all of which co-exist. At the end of his article, Sprenger hints that these religious beliefs will be reinvented with changes in political circumstances $(2006,13)$. This is an interesting topic to pursue and it may be worthwhile to examine how religious beliefs are being reinvented with agricultural transitions, especially given the integrated and holistic nature of highlander beliefs that Kirsch and Sprenger demonstrate. My paper attempts to answer precisely this question of how religious beliefs in response to changes in agricultural techniques. Such a study will not only enhance the general understanding of highland societies, but will also allow us to gain a better understanding of how tribes negotiate with the state, and correspondingly characterise state-minority relations.

\section{Methods}

Based on the theoretical frameworks identified in the literature discussed above, the following research questions were formulated:
- What is the connection between agriculture and the religious beliefs of the Khmu?

- How have the Khmu reinvented their religious beliefs in response to changes in agriculture?

- What can be understood from this reinvention about how minorities negotiate with the state?

The research design was divided into the segments shown in the diagram below. Ethnographic data were collected in order to be able to specify the relationship between religion and agriculture and to understand how religion is being reinvented. Both of these were then used to characterise state-minority relations.

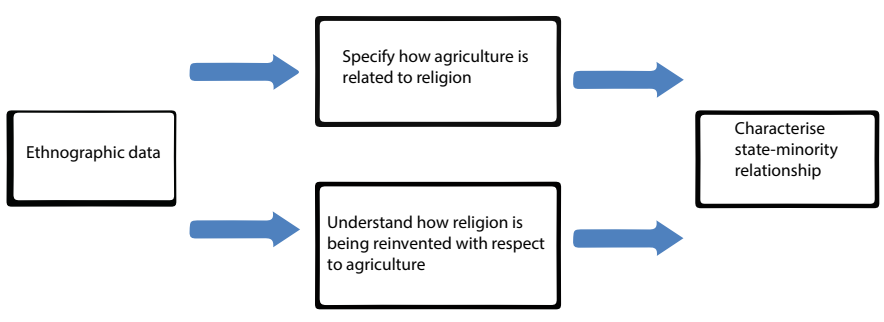

Figure 1: Schematic representation of research design

To conduct this qualitative research, I carried out ethnographic fieldwork carried out over three weeks in June 2013 among highland minorities in Laos and Thailand. Fieldwork involved using ethnographic methods in the form of interviews and observations.

I conducted interviews with various types of villagers such as the village headmen, elders and farmers. Initially, I sought to obtain information on how agricultural rituals were performed traditionally (before state driven agricultural transitions) from the older generation of villagers. During subsequent interviews with farmers, I obtained similar data for current practices, and then compared the religious practices involved in (or absent from) subsistence and commercial farming. I then explored the reasoning 
behind differential religious practices between swiddening and lowland agriculture. Further, I investigated the farmers' motivations for choosing the type of agriculture that they engaged in. Lastly, I interviewed female household heads in order to explore dimensions of sanctity in household consumption of farmed crops (from both swidden and lowland farming). Interviews were conducted with the assistance of translators who were competent in Lao and English.

Data was also collected through observations of farming practices and religious rituals whenever possible. Procedures I observed include the burning of vegetation on upland farming plots, the planting of the first rice at the start of season for lowland paddy farming and soul-calling rituals to cure sick individuals.

\section{Village Profiles}

Three Khmu Villages in the Vieng Phouka district (VPK) of the Laung Namtha province in Northern Laos served as the primary sites of data collection. A single Khmu Village in the Nan Province of Thailand was chosen to be the secondary field site for comparative purposes. While I was unable to draw any conclusions regarding the differential experience of the Khmu in the two states, data collected from both sites were useful in elucidating the connection between religion and agriculture in the Khmu society. Table 1 summarises the profiles of the four villages where fieldwork was conducted.

\section{Table 1: Village Profiles}

\begin{tabular}{|l|l|l|}
\hline Villages & Location & $\begin{array}{l}\text { Population } \\
\text { (house- } \\
\text { holds) }\end{array}$ \\
\hline Village A & VPK, Laos & 87 \\
\hline Village B & VPK, Laos & 108 \\
\hline Village C & VPK, Laos & 140 \\
\hline Village D & Nan, Thailand & 101 \\
\hline
\end{tabular}

Table 2: Percentage of Villagers engaging in type of farming

\begin{tabular}{|l|l|l|l|}
\hline Villages & $\begin{array}{l}\text { Only Swidden } \\
\text { farming }\end{array}$ & $\begin{array}{l}\text { Swidden and } \\
\text { Paddy Farm- } \\
\text { ing }\end{array}$ & $\begin{array}{l}\text { Only paddy } \\
\text { farming }\end{array}$ \\
\hline Village A & $31 \%$ & $67 \%$ & $2 \%$ \\
\hline Village B & $23 \%$ & $74 \%$ & $3 \%$ \\
\hline Village C & $41 \%$ & $45 \%$ & $14 \%$ \\
\hline Village D & - & - & - \\
\hline
\end{tabular}

*Village D consisted mainly of upland farming of mono crops as its land is located at higher altitudes with limited access to lowland fields.

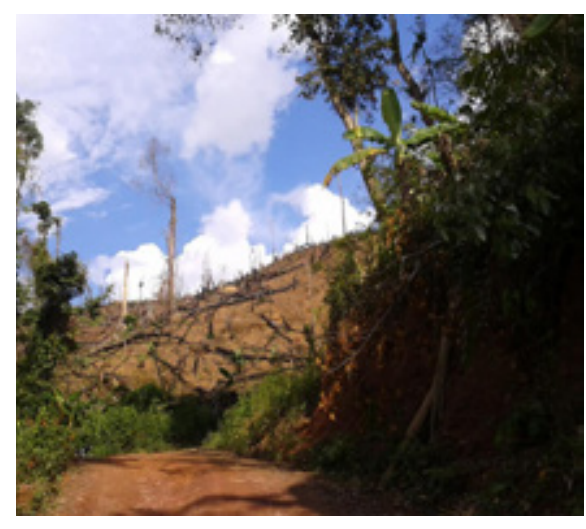

Photo Credit: Anjana Ramkumar

Figure 2: A plot of swidden land that had been cleared with fire. 


\section{Research Findings}

Sanctity and Secularity in Agriculture

In all three Khmu villages of Laos, upland rice produced from swidden farming is sacred. This sacredness is manifested in rituals that are conducted annually as part of the farming cycle. Known as 'hep-pi' in Khmu, three of these rituals are carried out during the farming process: the first before the sowing of seeds, the second before harvesting rice and the third when the rice is brought back to the village. The first two rituals are performed for the farm spirit in the fields, to whom villagers pray for good quantity and quality of rice - 'beautiful rice' as described by the Khmu. This process is known as 'Hae Kwan' or 'soul making' in the local language, as rice is traditionally believed to have a soul. The last ritual takes place in the village, where villagers pray to the village spirit for economical consumption of rice, such that it lasts for the longest time possible. Important steps in the farming cycle such as clearing forest lands and planting the rice are done on auspicious days. When asked the reason behind the sanctity of rice, an elder from Village A replies 'It is just like that - Rice is sacred because it is important to us.' Rituals are then explained by the presence of spirits in the hills and that their help is necessary for good yields of such important crops.

The label of sanctity however, is exclusive to upland rice. As a contrast, paddy rice, grown on lowland plots, is not considered sacred. While villagers acknowledged that paddy rice has a soul as well, questions on whether spirits will help paddy rice grow were usually met with strange stares or slight laughter. While swidden farming ties in closely with the spirits, paddy field farming is purely procedural to the $\mathrm{Khmu}$, with no rituals being performed. When asked about it, a farmer from Village A replies 'Wetland rice has a much simpler process of using tractors and I just start to plant whenever there is water'. Similarly, another farmer from Village $\mathrm{C}$ states 'If I follow the procedure and give the rice enough water, I will get 'beautiful rice on the paddy fields'. Thus, responses indicate a guaranteed yield of rice as long as procedures are followed, as opposed to swidden which is dependent on the blessing of spirits. Additionally, automation is also used to explain secularity of paddy rice, whereby a Khmu teenager from Village A reasons that manual labour makes hill rice sacred whereas automation makes paddy rice secular.

Vegetables fall into the same category of secularity as paddy rice, although they are believed not to have souls. While some vegetables, especially cash crops, were introduced recently to the Khmu, a few varieties such as tubers and bamboo have been traditionally part of Khmu societies, but at no point were they sacred. Rubber trees are planted by approximately $80 \%$ of the households in the three villages and rubber cultivation is completely secular. As a 27-year old farmer from Village A explains, ' $[\mathrm{He}]$ will plant the rubber seeds whenever he gets it from the Chinese investor (as opposed to choosing the auspicious time). [He] just has to make sure that there is enough water for the seeds. Perhaps what is most indicative of secularisation in agriculture is the rationalisation of yields by the Khmu. If paddy crops don't grow well, lack of water resources or pests are used to reason it as opposed to hill rice where low yield is connected with the anger of spirits. Correspondingly, to rectify the situation, while other crops require fertilisers and pesticides, hill rice demands rituals asking for the blessings of the spirits. Considering that the majority of Khmu households practiced lowland farming, a significant portion of agriculture is thus now secular.

In identifying the criteria that determine the sanctity of crops, the circumstances of such religious labelling have to be considered in the right temporal context. In this case, the question is to understand why swidden rice was sacred to the Khmu in the past when they were living in higher altitudes. Recollections of life in the hills by the elders suggest that the sacredness of an entity stems from the risk that mode of living carries. When a farming system carries a substantial amount of risk, this risk is mitigated by spirit worship, whereby the Khmu 'control' the risk by praying 
to the spirit. The idea of risk consists of two aspects - the fragility of the system and the stakes invested in the harvest. Fragility of the system refers to how susceptible it is to environmental variations, while stakes refer to the consequences of low yield. Swidden rice classifies as risky under both these aspects. Most villagers describe their swidden yields as being more variable, whereas paddy yields are approximately the same amount of rice annually. Moreover, soil quality is extremely important for swidden fields, but farmers can do little to control it as fertilisers are not used in the production of upland rice. Weeding has to be done manually as herbicides are ineffective on highlands, making it tedious as well as more susceptible to human error. While such conditions contribute to the fragility of the swidden system, there were also high stakes in upland farming in the past. Being the staple food for the $\mathrm{Khmu}$, rice was absolutely essential to survival. A failing harvest could then mean dire consequences for the household. Thus, upland rice was revered to be sacred, as a form of negotiating these uncertainties through spirit worship. To a large extent, farming conditions in the hills remain the same, and though the stakes are lower now due to the addition of paddy farming, the sanctity of upland rice is largely maintained as a form of tradition.

The same concept of risk can then also be used to explain secularity. Tubers and bamboo shoots, which were part of the traditional $\mathrm{Khmu}$ diet, were obtained easily. According to a Khmu elder in Village B, 'tubers grew naturally' and took less effort than rice. Bamboo shoots meanwhile were abundant in the forests to be foraged. Paddy farming is stable due to automation, use of fertilisers and easy weeding, all of which ensure consistency in yield. The use of tractors in particular not only stabilises yield but also makes the farming process much easier than swidden, reducing the need to pray for the spirits' help. This also explains why many Khmu cited automation as the reason for paddy rice's secularity. Vegetables are grown with fertilisers as well, in smaller quantities and with lower stakes such that they remain secular.
However, when the stakes of cash crops increase, the greater risk that is then entailed pushes them towards sanctity. While recent cash crop introductions are conceptualised as secular by the $\mathrm{Khmu}$ in Laos, animal feed corn has attained a status of sanctity amongst the Khmu in Thailand. In Village $\mathrm{D}$, farmers grow corn as a monocrop, which serves as their primary source of income. While they use herbicides to combat weeds, the corn remains susceptible to pests such as field mice which can destroy the entire field. Corn farmers obtain loans to support their farming and many are stuck in debt cycles for years as their yearly revenue is not sufficient to settle their loans. One year of crop failing can thus have dire consequences, potentially depleting their financial resources. Given the high stakes and the vulnerability of the corn to pests, Khmu conduct rituals to pray for its protection. As such, $\mathrm{Khmu}$ continue to use religion to mitigate risk as exemplified by the modern reinvention of this traditional reasoning.

Conversely, a reverse process is taking place among the Khmu of Vieng Phouka, whereby swiddening is becoming more secular.The main rationale behind this is the fact that villagers are no longer dependent only on swiddening for rice, following the introduction of paddy farming. As such, the importance and correspondingly the stakes invested in swiddening drop, such that many villagers have a choice to stop or to limit their swiddening activities. Fieldwork reveals that practicality and convenience are the main deciding factors as to how much swidden the villagers do, as opposed to religious rationalisation which might be expected given that hill rice is a sacred entity. A middle-aged farmer from Village B, for instance, owns fiveplots of swidden land but did not do swidden farming for the past three years as the land was too far away. He resumed again this year as the plot of land happened to be near the village according to the swidden rotation. In addition to the long distance, other villagers cite the difficulty of farming in the hills and the lack of labour as reasons for stopping or decreasing swidden. These factors coupled with the fact that they now have an easier alternative make swiddening a burden that they are no longer forced to carry. 


\section{Economic Rationalisation}

Regardless of the sanctity or secularity of farming, transition to the commercial economy has resulted in one major change - the $\mathrm{Khmu}$ are no longer farming for food alone but also for money. As a result, agriculture is linked to commercial value such that the Khmu now rationalise economically when it comes to farming. This is exemplified by a young farmer in Village $C$ who does not do any swidden farming as according to him, paddy fields have more value for time as opposed to swidden land - a reasoning based on efficiency. Because of the low value that swidden plots yield, many of the younger generation prefer to earn wages as opposed to swidden farms, especially in the poorer households. An 80 year old farmer from Village B who farms on his swidden land alone complained of its many difficulties during an interview. When asked why his grandchildren are doing wage labour instead of helping him farm, he replies 'Money is more important in the end, rice is just for consumption and is not enough to buy other things'. A Khmu teenager in Village A also expresses views that the main purpose of paddy rice is to be sold, such that the money can be used for other commodities. These responses show that acquiring money is seen as an important goal of farming, although consumption remains an important factor. The Khmu are thus basing choices in agriculture on the monetary value of farming as opposed to purely on consumption needs. Economic rationalisation is an important change of mindset that is taking place along with secularisation, both of which are partly replacing the idea of sacredness.

Mindset changes are not necessarily confined to specific domains of a society, and the Khmu are now mobilising economic rationalisations in other aspects as well. Such rationalisation is also applied to religious beliefs, as manifested in the conduct of rituals. Ritual sacrifices are commonplace in Khmu society when a villager falls sick. Sickness is reasoned as a result of offending the spirits, and animals are sacrificed to seek forgiveness from them. However, while rituals in the past involved sacrifices of animals of all sizes, depending on the nature and severity of sickness, present day Khmu sacrifice only smaller animals like chickens and pigs, which have lesser economic value. This is partly due to the discourses of government campaigns to discourage sacrifices. As one Khmu farmer describes the government's advice, 'Even if you kill a cow, the sick don't recover. Instead of wasting the cow, you can sell the animal and use the money elsewhere'. Information obtained from a few interviewees shows a decline in sacrifices, especially of cows or buffalos, indicating that villagers are accepting the economic rationalisation presented by the state. One villager from Village $\mathrm{C}$ said that when he was younger they used to kill ten to fifteen buffalos a year, but now for the past five years there have hardly been any sacrifices. In the event that cows need to be sacrificed, villagers buy one to two kilograms of beef from the market, as opposed to sacrificing cows from their own herds.

A second instance of such rationalisation is seen in soul-calling rituals. The Khmu believe that when a person falls sick, they can be cured by 'calling their soul' back. In these rituals, it is now commonplace to tie Laotian currency to sacred threads, which are then tied around the hands of the sick personby family and friends. The addition of currency to what was previously a plain thread is a gesture to help the sick one's family financially, to cope with expenses that they may incur. Illness is no longer an issue of only bodily ailment but also carries with it an aspect of monetary cost.

In perhaps what can be seen as an extension of this religious economic rationalisation, Khmu in Thailand negotiate with the spirits using Thai currency. When a villager is ill, the shaman of Village D will go to the forest to pick out herbs to treat the patient. In this process, he leaves 25 baht in the forest for the forest spirit as an exchange for the herbs. Such financial transactions with the spirits are evidence that economic rationalisation is not mutually exclusive from religion, but rather is applicable even to negotiations with the spirits. 


\section{Amalgamation of Views as a Form of Adaptation}

While the scope of this research is not broad enough to understand the worldview of the Khmu completely, it does provide insight into the interaction between the traditional and the modern that is shaping this worldview. The application of economic rationalisation to religious beliefs and evolving notions of sanctity and secularity within agriculture reveal an amalgamation of religion and modern rationalisation. Not only do the two co-exist in the same society, but also they combine in many instances, such that modern thoughts are applied onto religious beliefs and vice-versa. Examples of this include the economic rationalisation of religious rituals and the spirit worship of a cash crop.

However, such amalgamations do not mean that there are no contradictions between religion and modernity. Rather, they illustrate how these contradictions are negotiated. In the case of the Khmu, this is done by adaptations which combine religion and modernity to maximise benefits. For instance, the economic rationalisation of religious rituals allows one to save money, and interestingly spirit-belief allows it as the Khmu believe the spirits would not be offended by receiving a smaller animal in sacrifice. (Such religious notions are also observed in secularisation, whereby the corresponding lack of spirit worship does not offend the spirits; prayer is deemed necessary only when you need the spirits' help). On the other end of the spectrum, sanctity of corn provides a religious outlet to manage risk, and spirits are believed to help the corn regardless of the fact that it is a non-traditional cash crop. Such maximising adaptations are therefore facilitated by religious conceptions that do not consider spirits as being opposite to modernity, but instead allow the two to combine.

It should be noted that adaptations are variable between households, as each has its own variation of a more or less shared belief system. For example, a unique adaptation was exhibited by a farmer-cum-businessman in Village $\mathrm{C}$, who serves as the middleman between Chinese investors and farmers in the village. While presumably well integrated into the market economy, which requires economic rationalisation, he was the only one amongst all interviewees who performed spiritual rituals for his paddy fields. In his words, 'I am afraid that my paddy rice will not grow well if I fail to 'hep-pi'. Thus, he uses religion as a way to ensure success in his economic endeavour. Adaptations may therefore occur in different ways but the combination of modern and 'Khmu' elements to benefit oneself is the common ideology that strings them together.

\section{Conclusion: State-Minority Relations as Strategic Engage-} ment to Maximise Benefits

The development of distance-demolishing technologies (roads in the case of the Khmu) has made it impossible for highland minorities to remain untouched by the state and the corresponding modernisation that is brought along with it (Scott 2009, 11). This paper investigated how lines between the sacred and the secular are drawn and redrawn in agriculture in relation to changes driven by the state. In contrast to the past, when every aspect of the society was sacred, there is now a significant extent of secularisation in agriculture amongst the Khmu of Northern Laos. Further, religious rituals and their corresponding 'sanctity', which were traditionally used in high risk scenarios as a way of dealing with uncertainty, continue to be applied under certain circumstances in commercial agriculture as well. Economic rationalisation has also been adapted into the society, which was previously rationalized in religious terms. Modern elements have influenced and at the same time have been influenced by religious beliefs, which can be understood as a way of negotiating the contradictions between the two.

What do these developments tell us about state-minority relations? The amalgamation of the modern and traditional, and the way such amalgamations are carried out in ways that are adaptive for the Khmu individual and society, reflect a strategic agency displayed by the Khmu in their negotiations with the state, 
partly echoing Scott's argument (2009). In this strategic agency, however, they are also embracing the state's intervention on some level, as seen from their acceptance of commercial agriculture, the inclusion of economic rationalisation in religious practices and their voluntary rejection of swiddening due to its tedious nature whenever possible, in conjunction with the land reforms led by the state. In the context of the Khmu then, minorities seem to be strategising actively to reap the most benefits that they can from the state, as observed by La-orngplew (2010), and falling outside the freedom-oppression dichotomy, as Jonsson (2012) suggests.

Going beyond transactions between the state and the Khmu society, however, such modernisation and the Khmu's response to it is shaping the very identity of this minority group, especially in this particular domain of religion which underpins its people's worldview. As one villager puts it 'we Khmu are not the same, we live our lives according to change.' Change may therefore be part of the Khmu identity, or rather one that is actively being adopted by them in the face of inevitable modernisation.

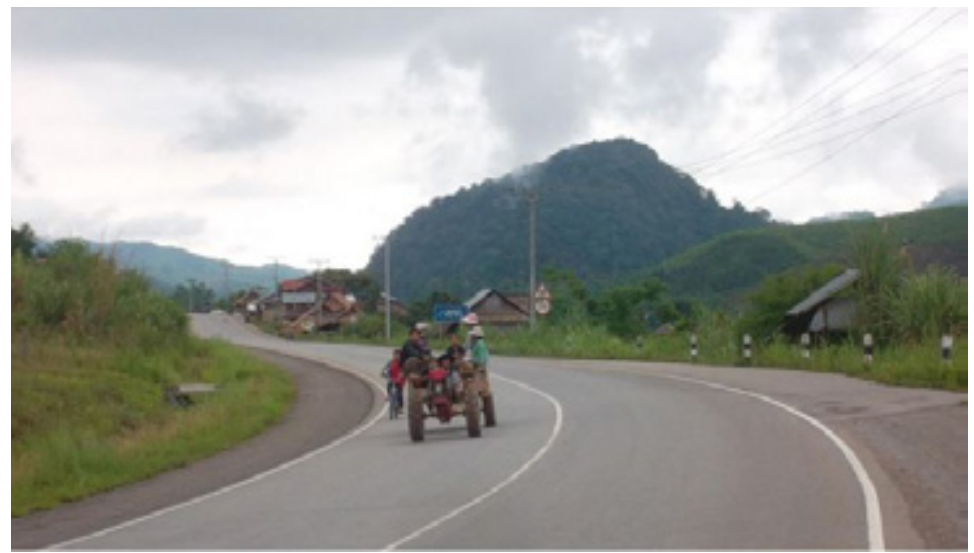

Photo Credit: Anjana Ramkumar

Figure 3: A Khmu family traveling to their paddy field on newly constructed roads. 


\section{ACKNOWLDEGEMENTS}

I would like to thank the Khmu villagers at my four field sites for their warm hospitality and for allowing me a glimpse into their world. My sincere thanks also goes to my supervisor A/P Peter Vail for his guidance with this project.

\section{REFERENCES}

Jonsson, Hjorleifur. 2012. "Paths to freedom: Political Prospecting in the ethnographic record. "Critique" of Anthropology 32 no. 2: 158-172.

Kirsch, A. Thomas. 1973. Feasting and Social Oscillations. A working paper on Religion and Society in upland Southeast Asia. New York: Southeast Asia Programme, Dept of Asia Studies, Cornell University.

La-orngplew, Wasana. 2010. Civilising the uplands: Development of Rubber plantations in remote areas of Lao PDR. RCSD International Conference: Revisiting Agrarian Transformations in Southeast Asia: Empirical, Theoretical and Applied Perspectives. Chiang Mai, Thailand.

Phonsena, Vatthana. 2005. "A Liberal model of Minority Rights for an Illiberal Multiethnic State? The case of Lao PDR."In Multiculturalism in Asia, edited by Will Kymlickaand Baogang He, 80-109. New York: Oxford University Press.

Scott, James. C. 2009. The Art of not being Governed: An Anarchist history of Upland Southeast Asia. New Haven: Yale University Press.

Sprenger, Guido. 2006. “Out of the Ashes.” Anthropology Today22 no.4: 9-13.

Thongmanivong, Sithong and Yayoi Fujita. 2006. "Recent Land Use and Livelihood Transitions in Northern Laos.” Mountain Research and Development 26 no.3: 237244 . 